\title{
Is Trehalose an Effective Quenching Agent of Azotobacter vinelandii Mo-Nitrogenase Turnover?
}

\author{
Leland B. Gee, ${ }^{\Uparrow}$ Aubrey Scott, Christie H. Dapper, ${ }^{\dagger}$ William E. Newton, ${ }^{\dagger}$ \\ and Stephen P. Cramer $\rrbracket_{, \neq} \neq *$
}

"Department of Chemistry, University of California, Davis, CA 95616

¥ Physical Biosciences Division, Lawrence Berkeley National Laboratory, Berkeley, CA 94720

${ }^{\dagger}$ Department of Biochemistry, Virginia Tech, Blacksburg, VA 24061

\begin{abstract}
$\mathrm{H}_{2}$-evolution assays, plus EPR and FTIR spectroscopies, using CO-inhibited Azotobacter vinelandii Mo-nitrogenase have shown that the disaccharide trehalose is an effective quenching agent of enzymatic turnover and also stabilizes the reaction intermediates formed. Complete inhibition of $\mathrm{H}_{2}$-evolution activity was achieved at $1.5 \mathrm{M}$ trehalose, which compares favorably to the requirement for $10 \mathrm{M}$ ethylene glycol to achieve similar inhibition. Reaction-intermediate stabilization was demonstrated by monitoring the EPR spectrum of the 'hi-CO' form of COinhibited $\mathrm{N}_{2}$ ase, which did not change during $1 \mathrm{hr}$ after trehalose quenching. Similarly, in situ photolysis with FTIR monitoring of 'hi-CO' resulted in the same 1973 and $1681 \mathrm{~cm}^{-1}$ signals as observed previously in ethylene glycol-quenched systems.[a] These results clearly show that 1.5 $\mathrm{M}$ trehalose is an effective quench and stabilization agent for Mo- $\mathrm{N}_{2}$ ase studies. Possible applications are discussed.

[a.] "Photolysis of Hi-CO Nitrogenase - Observation of a Plethora of Distinct CO Species Using Infrared Spectroscopy", Yan, L.; Dapper, C. H.; George, S. J.; Wang, H.; Mitra, D.; Dong, W.; Newton, W. E.; Cramer, S. P., Eur J Inorg Chem, 2011, 2064-2074.
\end{abstract}

Keywords: Mo-nitrogenase, trehalose, EPR, FTIR, photolysis, carbon monoxide

- Corresponding author: spjcramer@ucdavis.edu 


\section{Introduction}

Polyols have long been used in studies with biological materials. Their major uses include protection from denaturation either on freezing (cryo-protection) or during relatively severe purification techniques that could damage the often fragile structure of polypeptide or prosthetic group or both. More recently, polyols have been used to probe catalytic questions by stabilizing reactive intermediates and so allowing studies that would otherwise be impossible or impracticable. In the nitrogenase field, glycerol and ethylene glycol have been the polyols of choice with the latter being used very effectively both to quench Mo-nitrogenase (Mo- $\mathrm{N}_{2}$ ase) activity and to stabilize three EPR-observable CObound intermediates[1-4] and one EPR-silent CO-bound intermediate. [5]

These experiments have proved their considerable worth by providing direct insight into substrate binding $[3,5,6]$ because, although CO has long been known as a potent inhibitor of $\mathrm{N}_{2}$ ase[7], it came as a surprise when it was recognized quite recently as a substrate.[8] Its reduction products include $\mathrm{CH}_{4}, \mathrm{C}_{2} \mathrm{H}_{4}, \mathrm{C}_{3} \mathrm{H}_{6}$, and even $\mathrm{C}_{4}$ species.[9-11] This resemblance to Fischer-Tropsch catalysis[12,13] has reinvigorated interest in the mechanism of biological nitrogen fixation, which is responsible for providing about half of the fixed nitrogen available globally.[14,15] But even more startling is the very recent crystallographic result, where the structure of a CO-bound form of Mo-N2ase showed that CO binding to the FeMo-cofactor (Scheme 1, left) was at the expense of a bridging 'waist' sulfide, which somehow regained its place, along with full enzymatic activity, when CO was removed.[16]

However, ethylene glycol and glycerol have their drawbacks; one being the difficulty in removing them from aqueous solutions when, for example, a very concentrated solution or a film of the substance of interest is required. Our search for a more tractable alternative led to a very different polyol, trehalose. Trehalose is a non-reducing homodisaccharide formed by linking two glucose molecules via a $\alpha$-1,1-glycosidic bond (Scheme 1, right), but has similar quenching and stabilizing properties.[17,18] It is found in microorganisms, plants and animals, often produced in response to environmental stress.[19] Trehalose treatment has been used previously to suppress protein relaxation between different CO- 
myoglobin conformations, even at room temperature and, at different concentrations, can even affect the proportions of CO species captured by myoglobin. [20,21] In addition, a trehalose-based glass has allowed capture of photo-intermediates of rhodopsin at room temperature that are ordinarily seen only at low temperatures or on short-time scales.[22] These observations suggested that trehalose treatment might be the alternative polyol for quenching $\mathrm{N}_{2}$ ase turnover and capturing intermediates that we were searching for. Here, we show that is indeed the case.
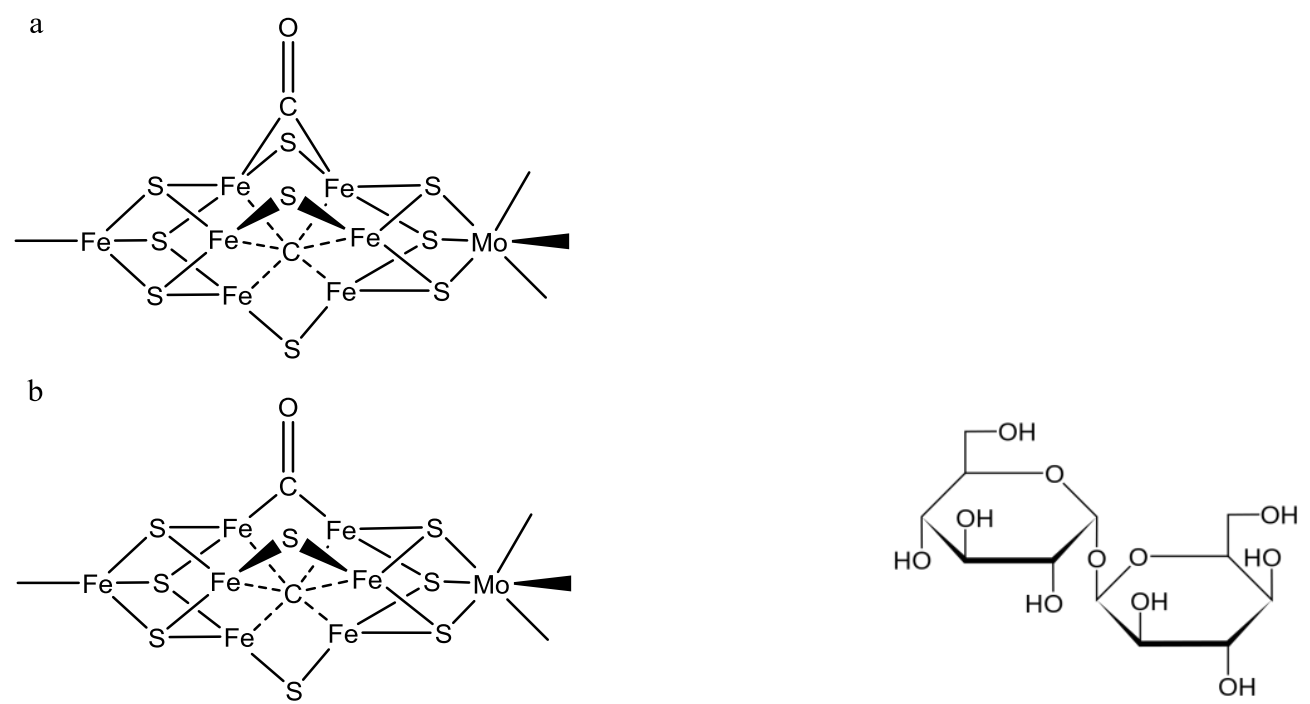

Scheme 1. Left: alternative structures of mono-CO-bound FeMo-cofactor (called 'lo-CO') with: (a) all three 'waist' bridging sulfides (S) in place [3,23]; and (b) with one 'waist' bridging S replaced by C0.[16] Right: structure of trehalose.

\section{Materials and Methods}

\subsection{Cell growth and protein purification}

The Azotobacter vinelandii wild-type strain (DJ527) was grown in a $24-\mathrm{L}$ fermenter at $30^{\circ} \mathrm{C}$ in a modified fixed-nitrogen-free liquid Burk medium.[24] The $\mathrm{N}_{2}$ ase component proteins were separated and purified as described previously.[25] All subsequent protein manipulation was done anaerobically with either a Schlenk line or within an anaerobic 
glove box operating at less than $1 \mathrm{ppm} \mathrm{O}_{2}$. The component proteins were concentrated individually using an Amicon microfiltration pressure concentrator before buffer exchange to $25 \mathrm{mM}$ HEPES (pH 7.4), $200 \mathrm{mM} \mathrm{NaCl}, 10 \mathrm{mM} \mathrm{MgCl} 2$ and $2 \mathrm{mM} \mathrm{Na}_{2} \mathrm{~S}_{2} \mathrm{O}_{4}$. The specific activity of the Fe and MoFe protein for hydrogen evolution was 2300 and 2100 nmoles $\mathrm{H}_{2}$ $\left(\mathrm{min}^{-1} \mathrm{mg}\right.$ protein $\left.{ }^{-1}\right)$ at $30^{\circ} \mathrm{C}$, respectively. Protein concentrations were determined using the Lowry method.[26]

\subsection{Trehalose suppression of catalyzed $\mathrm{H}_{2}$ evolution}

All wild-type MoFe-protein activities were measured using a high electron-flux assay that contained a 20 -fold molar ratio of wild-type Fe protein under an atmosphere of argon gas at $30^{\circ} \mathrm{C}$. Each assay contained $0.25 \mathrm{mg}$ total nitrogenase proteins, $30 \mu \mathrm{mol}$ of creatine phosphate, $25 \mu \mathrm{mol}$ of HEPES buffer (pH 7.4), $20 \mu \mathrm{mol}$ of sodium dithionite, $5 \mu \mathrm{mol}$ of $\mathrm{MgCl}_{2}, 2.5 \mu \mathrm{mol}$ of ATP, and $0.125 \mathrm{mg}$ of creatine phosphokinase. Trehalose solutions of varying concentrations were prepared in 25mM HEPES ( $\mathrm{pH}$ 7.4). Assays were quenched after 8 min by addition of an aliquot of either $0.5 \mathrm{M}$ EDTA to final concentration of $0.15 \mathrm{M}$ (as a control) or one of several trehalose solutions to achieve a final concentration of $0.2 \mathrm{M}$ to $1.5 \mathrm{M}$ trehalose. Total evolved $\mathrm{H}_{2}$ evolved was measured and the assays then remained at $30^{\circ} \mathrm{C}$ for up to 90 min more before total evolved $\mathrm{H}_{2}$ was again measured. Hydrogen was measured by an $8 \mathrm{~A}$ Shimadzu gas chromatograph using a molecular sieve $5 \mathrm{~A}$ column and a thermal conductivity detector with calibration by a standard $1 \% \mathrm{H}_{2}$ in $\mathrm{N}_{2}$ mixture.

\subsection{Trehalose stabilization of CO-bound species}

The so-called 'hi-CO' complex[2,3] was prepared by enzyme turnover under a $100 \%$ CO atmosphere using low electron-flux conditions generated by a 1:4 molar ratio of $\mathrm{Fe}$ protein:MoFe protein as described previously.[27] The reaction was then quenched by the addition of trehalose to a final concentration of $1.5 \mathrm{M}$ and the product concentrated in an Amicon microfiltration pressure concentrator under 100\% CO gas. 


\subsection{Electron paramagnetic resonance spectroscopy}

EPR spectra were collected at X-band using a Bruker CW Elexsys-II E500 instrument connected to a Bruker SHQE-W resonator at 12K. Cryogenic temperatures were achieved with an Oxford ESR-900 He-flow cryostat.

\subsection{Photolysis monitored by FT-infrared spectroscopy}

Photolysis was performed using a Sutter Instruments Lambda LS xenon-arc lamp and a Profoto ZoomSpot Flash Lamp essentially as performed previously.[5,27] Samples were held in custom-built $\mathrm{CaF}_{2}$-windowed cells with Teflon spacers giving a path length of 50 microns. Infrared spectra were recorded with a Bruker Vertex 70V vacuum FTIR instrument operating at $4-\mathrm{cm}^{-1}$ resolution. The samples were held at liquid helium temperatures inside a modified Oxford helium flow cryostat and photolyzed with 25-50 flashes of white light followed by direct illumination. The data are presented as difference spectra.

\section{Results}

\subsection{Effect of trehalose on enzyme activity}

Figure 1 shows the effect of adding either EDTA or trehalose as quenching agent on $\mathrm{N}_{2}$ ase activity. High electron-flux hydrogen-evolution assays are totally inhibited by addition of 0.15 M EDTA (final concentration), which is used as the control. Similar total inhibition of $\mathrm{N}_{2}$ ase activity also occurs with trehalose, but only at a final concentration of $1.5 \mathrm{M}$. Final concentrations up to $0.5 \mathrm{M}$ trehalose are ineffective and $1.0 \mathrm{M}$ only partially inhibitory. Values for total $\mathrm{H}_{2}$ evolved are normalized in Figure 1 to accommodate data from more than a single experiment. 


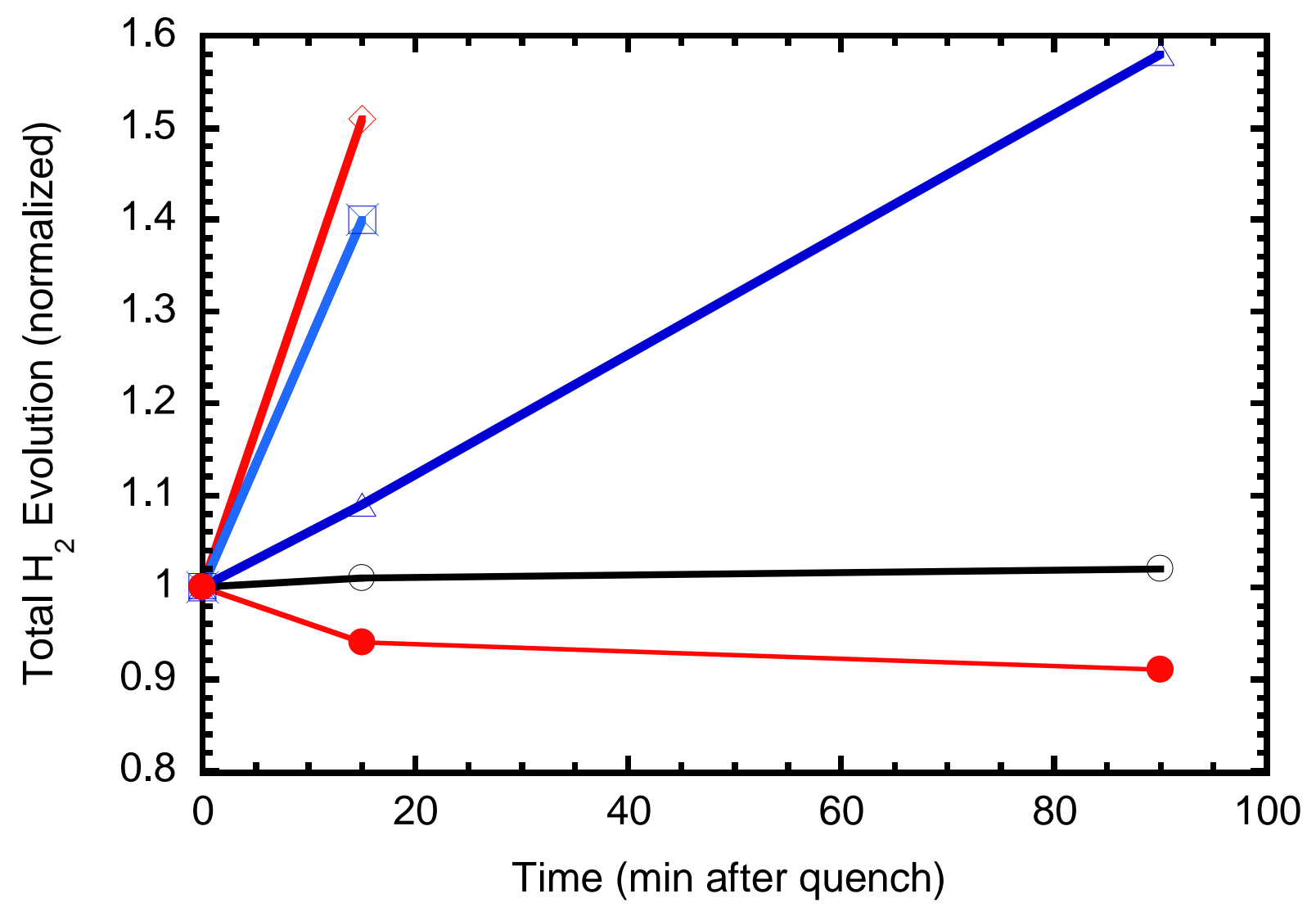

Figure 1. Plot of total $\mathrm{H}_{2}$ evolved (normalized to amount present at time zero) versus time (min after adding quenching agent); $\bullet=0.15 \mathrm{M}$ EDTA, $x=0.2 \mathrm{M}$ trehalose, $\square=0.4 \mathrm{M}$ trehalose, $\diamond=0.5 \mathrm{M}$ trehalose, $\Delta=1.0 \mathrm{M}$ trehalose, $\mathrm{O}=1.5 \mathrm{M}$ trehalose.

\subsection{Trehalose stabilization of the EPR signal from the 'hi-CO' inhibited form}

Figure 2 (bottom) shows the results of a low electron-flux turnover experiment under $100 \%$ CO. After $10 \mathrm{~min}$, an aliquot was removed and rapidly frozen before trehalose addition; it shows the axial EPR spectrum ( $\mathrm{g}=2.17,2.05$ ) of the expected 'hi-CO' form of COinhibited $\mathrm{N}_{2}$ ase.[2-4] This form has one terminally bound $\mathrm{CO}$ and a second CO-based ligand, possibly protonated.[27] Very low concentrations of both the 'lo-CO' form (visible as small baseline disturbances centered at $\sim 3650$ gauss) and the resting-state form (labeled as RS with $\mathrm{g}=4.3,3.7$ ) are also present. Immediately following the trehalose quench (to $1.5 \mathrm{M}$ final concentration), the integrated intensity of the $\mathrm{g}=2.17$ 'hi-CO' signal had decreased to 
$83 \%$ of the unquenched value, but was then stable for $1 \mathrm{hr}(77 \%)$. After $1.5 \mathrm{hr}$, about 55\% of its integrated intensity remained.

\subsection{FTIR-Monitored Photolysis}

Upon photolysis with broadband white light at liquid-helium temperatures, a trehalosequenched CO-bound Mo- $\mathrm{N}_{2}$ ase sample exhibited IR bands typical of the loss or rearrangement of bound CO ligands.[5,27] These changes are best illustrated in difference spectra as shown (Figure 2, top). The negative (downward) photolysis feature at $1973 \mathrm{~cm}^{-1}$ (Figure 2, top left) is due to loss of a terminally bound CO ligand, whereas that at and 1681 $\mathrm{cm}^{-1}$ (Figure 2, top right) reflects the re-arrangement of the second $\mathrm{CO}$ in the 'hi-CO' sample. The-positive (upward) feature at $1715 \mathrm{~cm}^{-1}$ (Figure 2, top right) is associated with the photolysis product and correlates with the formation of the 'lo-CO' species.[27] 


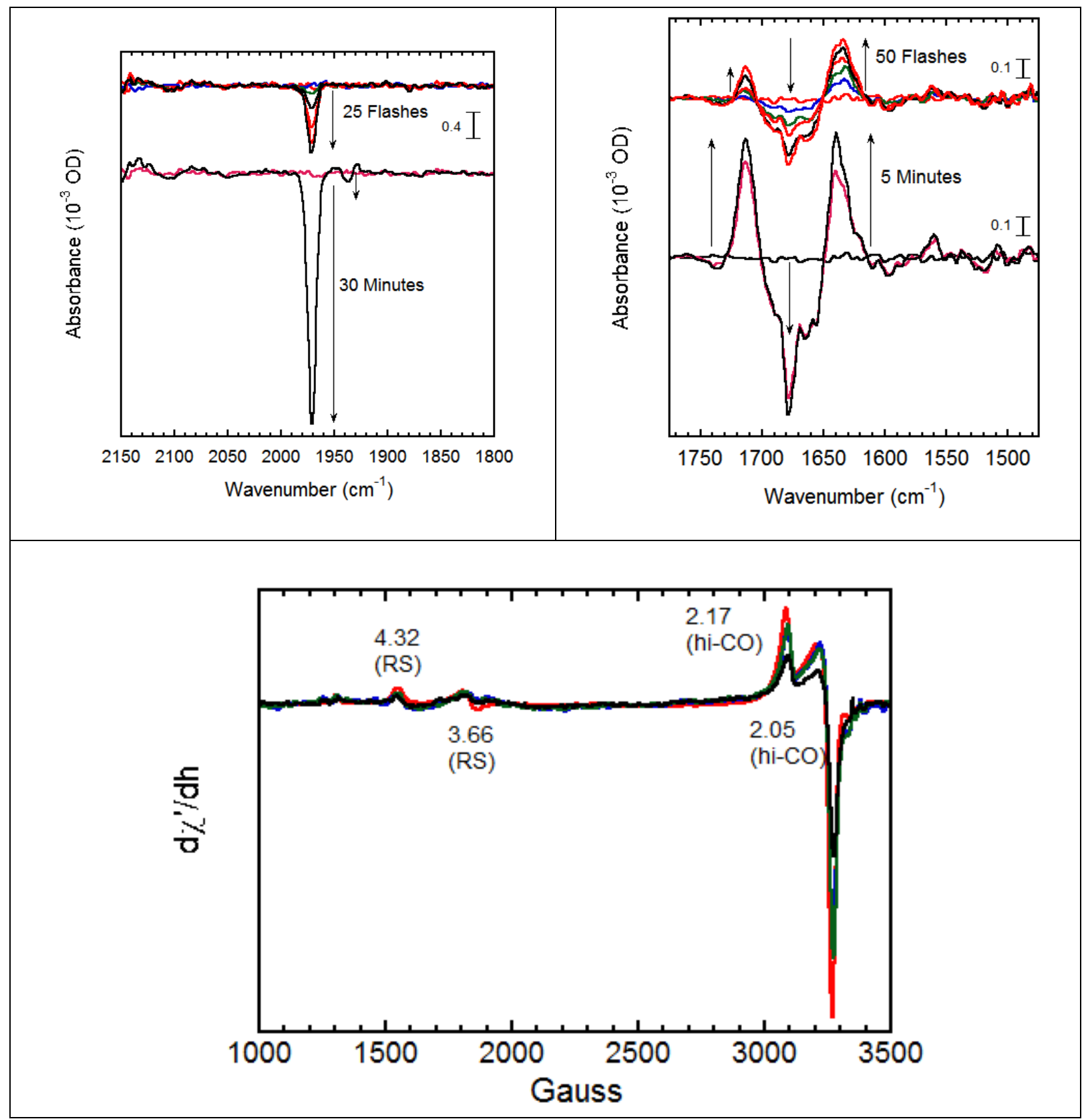

Figure 2. FTIR-monitored cryophotolysis and EPR Spectroscopy of the 'hi-CO' form of trehalosequenched $\mathrm{N}_{2}$ ase. Top: FTIR difference spectra for the high-energy (left) and low-energy (right) regions (see section 3.3 for band assignments). Bottom: Stacked EPR spectra for 'hi-CO' $\mathrm{N}_{2}$ ase: prior to trehalose quench (red); immediately after trehalose quench (blue); $1 \mathrm{hr}$ post quench (green); and $1.5 \mathrm{~h}$ post-quench (black). The g-values for the 'hi-CO' species and the small amount of 
resting-state (RS) enzyme are labeled. Spectra were corrected for concentration differences caused by dilution with the trehalose solution.

\section{Discussion}

The high electron-flux hydrogen-evolution assays clearly showed that $1.5 \mathrm{M}$ trehalose (final concentration) totally inhibits $\mathrm{N}_{2}$ ase activity. $\mathrm{No}_{2}$ production beyond that quench could be detected for up to $90 \mathrm{~min}$, which was not the case for final concentrations up to $1.0 \mathrm{M}$ trehalose. Three experiments (at $0.4 \mathrm{M}, 0.5 \mathrm{M}$ and 1.0 M trehalose) essentially produce the same total amount of $\mathrm{H}_{2}$, but over quite different time periods, which suggests that a limiting reactant in these assays, most likely dithionite or MgATP, has been exhausted by the time (15 min after the quench was added) of the first post-quench measurement. However, this observation does not negate the overall conclusion that trehalose is an effective inhibitor of $\mathrm{N}_{2}$ ase turnover.

The next question was whether trehalose additionally provides stability to any reaction intermediate trapped by its cessation of turnover. We approached this question by using two techniques with which we are very familiar, in combination with two well-known forms of Mo-N2ase, namely its CO-inhibited forms called 'hi-CO' and 'lo-CO'.[1-5,27] First, we were encouraged by the results of monitoring a sample of 'hi-CO' using EPR spectrosopy, when found that, after 1.5 M trehalose quenching, the spectrum was stable for up to $1 \mathrm{hr}$. Then, we applied FTIR-monitored cryophotolysis to 'hi-CO' to determine its response to white-light illumination. To our satisfaction, we found negative (downward) photolysis features at $1973 \mathrm{~cm}^{-1}$ and $1681 \mathrm{~cm}^{-1}$, both of which indicate loss or rearrangement of $\mathrm{CO}$ from two different binding sites on the sample plus a positive (upward) feature at $1715 \mathrm{~cm}^{-1}$ (see Figure 2, top right) which is associated with the photolysis product, 'lo-CO'. These results are essentially the same as those previously reported for ethylene glycol-quenched CO-inhibited $\mathrm{N}_{2}$ ase.[5,27]

These experiments clearly show that trehalose is an effective quench for $\mathrm{Mo}-\mathrm{N}_{2}$ ase studies at $1.5 \mathrm{M}$, which compares favorably to the requirement for $10 \mathrm{M}$ ethylene glycol to achieve similar inhibition. They also confirm what we had expected from both earlier 
studies on CO-myoglobin[17,18,20,21] and from its recognized role as a stress protectant in many biological systems.[19] Furthermore, there is microbiological evidence for trehalose quenching $\mathrm{N}_{2}$ ase activity. For example, it was found that increased root-nodule trehalose production coincided with decreased catalyzed acetylene-reduction activity in symbiotic systems involving Rhizobium during drought-like conditions.[28]

The mechanism by which trehalose inhibits nitrogenase activity and stabilizes reaction intermediates remains unknown. However, previous studies, using all-atom molecular dynamics for trehalose, indicate that $1.5-2.2 \mathrm{M}$ solutions cause formation of large, recursively associating aggregates.[29] The critical concentration for formation of these aggregates coincides with the concentration that results in $\mathrm{N}_{2}$ ase inhibition and, therefore, suggests that aggregation may play a role in trehalose's quenching ability.

From a practical standpoint, the goal of this work was to develop a system to produce high concentrations of materials that are currently not easily achieved by simple evaporation or other concentration methods. Toward this goal, we believe we have the beginnings of such a system using trehalose. The properties of trehalose open possibilities for such higher concentrations, which would make spectroscopic work on weaker vibrational, electronic, or nuclear features a real possibility. Likewise, analogous to work on myoglobin, there is the potential to stabilize and trap new forms of intermediates for spectroscopic studies that could help unravel the mysteries of substrate dynamics and/or kinetics that continue to appear in $\mathrm{N}_{2}$ ase-based research.

\section{Abbreviations}

$\mathrm{CW}$ - continuous wave

EPR - electron paramagnetic resonance spectroscopy

FTIR - Fourier-transform infrared spectroscopy

FeMo-cofactor - the iron-molybdenum cofactor of the MoFe protein

Fe protein - the iron protein of Mo-nitrogenase

MoFe protein - the molybdenum-iron protein of Mo-nitrogenase

Mo- $\mathrm{N}_{2}$ ase - molybdenum-based nitrogenase 
$\mathrm{N}_{2}$ ase - nitrogenase

\section{Acknowledgements}

This work was funded by National Institutes of Health Grant GM-65440, and the National Science Foundation grant CHE 1308384 (S.P.C.)

\section{References}

[1.] "Iron-Sulfur Clusters in the Molybdenum-Iron Protein Component of Nitrogenase. Electron Paramagnetic Resonance of the Carbon Monoxide Inhibited State", Davis, L. C.; Henzl, M. T.; Burris, R. H.; Orme-Johnson, W. H., Biochemistry, 1979, 18, 4860-4869.

[2.] "Investigation of $\mathrm{CO}$ binding and release from Mo-nitrogenase during catalytic turnover", Cameron, L. M.; Hales, B. J., Biochemistry, 1998, 37, 9449-9456.

[3.] "CO Binding to the FeMo Cofactor of CO-inhibited Nitrogenase: ${ }^{13} \mathrm{CO}$ and ${ }^{1} \mathrm{H}$ Q-band ENDOR Investigation", Lee, H.-I.; Cameron, L. M.; Hales, B. J.; Hoffman, B. M., Journal of the American Chemical Society, 1997, 119, 10121-10126.

[4.] "Ethylene Glycol Quenching of Nitrogenase Catalysis: An Electron Paramagnetic Resonance Spectroscopic Study of Nitrogenase Turnover States and CO Bonding", Hales, B. J., Biochemistry, 2015, 54, 4208-4215.

[5.] "IR-Monitored Photolysis of CO-Inhibited Nitrogenase: A Major EPR-Silent Species with Coupled Terminal CO Ligands", Yan, L. F.; Pelmenschikov, V.; Dapper, C. H.; Scott, A. D.; Newton, W. E.; Cramer, S. P., Chem-Eur J, 2012, 18, 16349-16357.

[6.] "Mechanism of nitrogen fixation by nitrogenase: the next stage", Hoffman, B. M.; Lukoyanov, D.; Yang, Z. Y.; Dean, D. R.; Seefeldt, L. C., Chem Rev, 2014, 114, 4041-4062.

[7.] "Mechanism of Biological Nitrogen Fixation. VIII. Carbon Monoxide as an Inhibitor for Nitrogen Fixation by Red Clover", Lind, C. J.; Wilson, P. W., Journal of the American Chemical Society, 1941, 63, 3511-3514.

[8.] "Vanadium Nitrogenase Reduces CO", Lee, C. C.; Hu, Y.; Ribbe, M. W., Science, 2010, 329, 642.

[9.] "Tracing the Hydrogen Source of Hydrocarbons Formed by Vanadium Nitrogenase", Lee, C. C.; Hu, Y. L.; Ribbe, M. W., Angewandte Chemie-International Edition, 2011, 50, 55455547.

[10.] "Molybdenum Nitrogenase Catalyzes the Reduction and Coupling of CO to Form Hydrocarbons", Yang, Z. Y.; Dean, D. R.; Seefeldt, L. C., Journal of Biological Chemistry, 2011, 286, 19417-19421.

[11.] "Extending the Carbon Chain: Hydrocarbon Formation Catalyzed by Vanadium/Molybdenum Nitrogenases", Hu, Y.; Lee, C. C.; Ribbe, M. W., Science, 2011, 333, 753-755.

[12.] "Fischer-Tropsch Chemistry at Room Temperature?", Gerlach, D. L.; Lehnert, N., Angewandte Chemie-International Edition, 2011, 50, 7984-7986. 
[13.] "First-Principles Calculations of Fischer-Tropsch Processes Catalyzed by Nitrogenase Enzymes", Varley, J. B.; Norskov, J. K., Chemcatchem, 2013, 5, 732-736.

[14.] "Distribution of nitrogen fixation and nitrogenase-like sequences amongst microbial genomes", Dos Santos, P. C.; Fang, Z.; Mason, S. W.; Setubal, J. C.; Dixon, R., BMC Genomics, 2012, 13.

[15.] "Recent Advances in Understanding Nitrogenases and How They Work", Newton, W. E., in Biological Nitrogen Fixation; John Wiley \& Sons, Inc, 2015, pp. 5-20.

[16.] "Ligand binding to the FeMo-cofactor: Structures of CO-bound and reactivated nitrogenase", Spatzal, T.; Perez, K. A.; Einsle, O.; Howard, J. B.; Rees, D. C., Science, 2014, 345, $1620-1623$.

[17.] "Effect of trehalose on protein structure", Jain, N. K.; Roy, I., Protein Science : A Publication of the Protein Society, 2009, 18, 24-36.

[18.] "New insights on trehalose: a multifunctional molecule", Elbein, A. D.; Pan, Y. T.; Pastuszak, I.; Carroll, D., Glycobiology, 2003, 13, 17R-27R.

[19.] "Trehalose in yeast, stress protectant rather than reserve carbohydrate", Wiemken, A., Antonie van Leeuwenhoek, 1990, 58, 209-217.

[20.] "Protein Reaction-Kinetics in a Room-Temperature Glass", Hagen, S. J.; Hofrichter, J.; Eaton, W. A., Science, 1995, 269, 959-962.

[21.] "Coupling between the Thermal Evolution of the Heme Pocket and the External Matrix Structure in Trehalose Coated Carboxymyoglobin", Giuffrida, S.; Cottone, G.; Librizzi, F.; Cordone, L., The Journal of Physical Chemistry B, 2003, 107, 13211-13217.

[22.] "Room-Temperature Trapping of Rhodopsin Photointermediates", Sikora, S.; Little, A. S.; Dewey, T. G., Biochemistry, 1994, 33, 4454-4459.

[23.] "Nitrogenase MoFe-Protein at $1.16 \AA$ Resolution: A Central Ligand in the FeMoCofactor", Einsle, O.; Tezcan, F. A.; Andrade, S. L. A.; Schmid, B.; Yoshida, M.; Howard, J. B.; Rees, D. C., Science, 2002, 297, 1696-1700.

[24.] "Formation of the nitrogen-fixing enzyme system in Azotobacter vinelandii", Strandberg, G. W.; Wilson, P. W., Canadian journal of microbiology, 1968, 14, 25-31.

[25.] "Role of the MoFe Protein Alpha-Subunit Histidine-195 Residue in FeMo-Cofactor Binding and Nitrogenase Catalysis", Kim, C. H.; Newton, W. E.; Dean, D. R., Biochemistry, 1995, 34, 2798-2808.

[26.] "Protein Measurement with the Folin Phenol Reagent", Lowry, O. H.; Rosebrough, N. J.; Farr, A. L.; Randall, R. J., Journal of Biological Chemistry, 1951, 193, 265-275.

[27.] "Photolysis of Hi-CO Nitrogenase - Observation of a Plethora of Distinct CO Species Using Infrared Spectroscopy", Yan, L.; Dapper, C. H.; George, S. J.; Wang, H.; Mitra, D.; Dong, W.; Newton, W. E.; Cramer, S. P., Eur J Inorg Chem, 2011, 2064-2074.

[28.] "Nitrogenase activity and trehalose content of nodules of drought-stressed common beans infected with effective (Fix+) and ineffective (Fix-) rhizobia", Zacarías, J. J. J.; Altamirano-Hernández, J.; Cabriales, J. J. P., Soil Biology and Biochemistry, 2004, 36, 19751981.

[29.] "Linking Trehalose Self-Association with Binary Aqueous Solution Equation of State", Sapir, L.; Harries, D., The Journal of Physical Chemistry B, 2011, 115, 624-634. 
We have observed using FTIR, EPR, and activity assays that trehalose quenches the nitrogenase reaction and stabilizes the formation of bound $\mathrm{CO}$ species. Trehalose has potential applications in increasing the concentrations of nitrogenase protein while maintaining spectroscopically interesting species. 


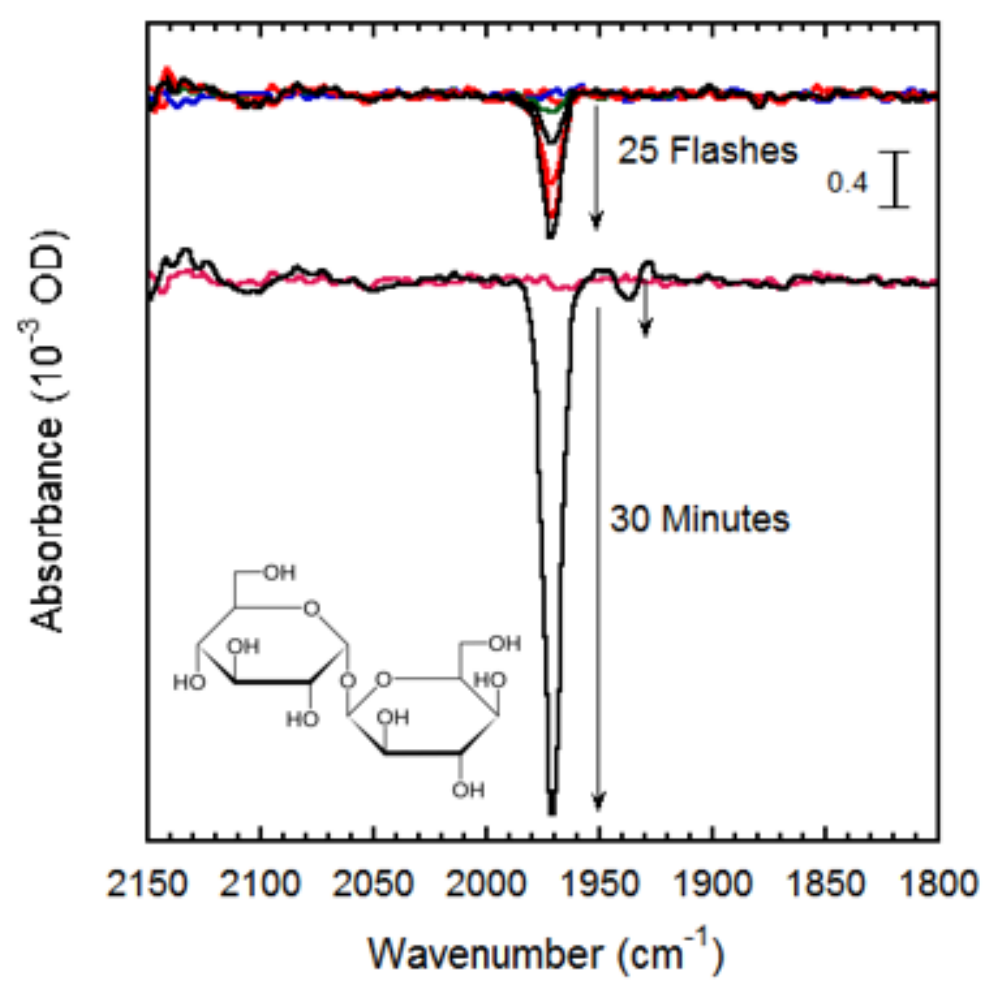

